\title{
Study Of Some Epidemiological Determinants Of Ocular Morbid Conditions In The Rural Area Of Central India.
}

\author{
Vaishali K Shrote ${ }^{1}$, (Mrs) Sushma S Thakre², Subhash B Thakre ${ }^{3}$, \\ Kishor P Brahmapurkar ${ }^{4}$,Vivekanand C. Giri ${ }^{5}$ \\ ${ }^{I}$ (Department of Preventive and Social Medicine,S. V. N. Government Medical College, Yavatmal [M.S] India) \\ ${ }^{2}$ (Department of Preventive and Social Medicine,Indira Gandhi Government Medical College, Nagpur \\ [M.S] India) \\ ${ }^{3}$ (Department of Preventive and Social Medicine, Government Medical College, Nagpur [M.S] India) \\ ${ }^{4}$ (Department of Preventive and Social Medicine,S. V. N. Government Medical College, Yavatmal [M.S] \\ India.) \\ ${ }_{5}^{5}$ (Department of Epidemiology and Statistics, Central Leprosy Teaching and Research Institute,Chengalpattu- \\ Tamil Nadu, India.)
}

\begin{abstract}
INTRODUCTION: Ocular morbid conditions are responsible for partial or total blindness. Ocular morbidities by its sheer magnitude form an enormous problem, not only in human suffering, but also in terms of economical loss and social burden.

OBJECTIVE: To study some epidemiological determinants of ocular morbidities in rural area.

MATERIAL AND METHODS: Present Community Based Cross-Sectional Study Was Undertaken In Rural Area Of Hingna,Nagpur District.This Study Was Carried Out In 194 Families With 925 Study Subjects During February 2005-December 2005. Diagnosis Of Ocular Morbid Condition Was Based On Standard Clinical Definitions And International Classification Of Diseases-10 (Icd-10).Both Eyes Were Examined And All The Relevant Clinical Findings Were Recorded In Predesigned Proforma.

RESULTS: The results revealed, overall prevalence of ocular morbidity was $32.11 \%$. Tobacco smoking and alcohol consumption habits were found in statistically significant $(p<0.05)$ association with ocular morbidity when compared with no habit .In female $53.71 \%$ of ocular morbid conditions were found in those biomass as cooking fuel.

CONCLUSION: High prevalence of ocular morbidities were found in rural areas of central India with greater predominance among lower socioeconomic strata and study subjects with tobacco smoking and alcohol consumption habits and in females predominantly using biomass as cooking fuel.
\end{abstract}

Key words: cular morbidity, Rural area, Determinants, Personal habits, Cooking fuel, SocioEconomic Status .

\section{INTRODUCTION}

Ocular morbid conditions are responsible for partial or total blindness. Loss of sight of a person should not remain just a statistic but a personal tragedy, not only for the individual concerned, but for all of us who claim to be concerned. Blindness and visual impairment by its sheer magnitude forms an enormous problem, not only in human suffering, but also in terms of economical loss and social burden. Blindness, with its social and economic consequences, represents a significant public health problem in many parts of the world [1].

Some of the ocular morbid conditions are cataract, refractive errors, Xerophthalmia, Pterygium, Strabismus, Dacryocystitis, etc.

In the changing concepts in eye health care, the epidemiological approach focuses, the measurement of the incidence and prevalence of diseases.

Surveys indicate that social factors responsible for blindness are ignorance, illiteracy; poverty, low standards of personal and community hygiene, smoking, alcohol consumption and inadequate health care services.

The role of smoking in cataractogenesis has been highlighted in various studies. Also alcohol consumption is a risk factor for cataract [2]. Approximately half the world's population and upto $90 \%$ rural households in developing countries still rely on unprocessed biomass fuels such as wood, dung and crop residues. It is believed that biomass fuel smoke results in the opacity of lens [3].

Vision 2020: The right to sight, it is a global initiative to eliminate avoidable blindness launched by WHO, on 18th Feb 1999 [4].

With this background, the present study was conducted to estimate the prevalence of ocular morbid conditions and to study some epidemiological factors . 


\section{MATERIAL AND METHODS}

A community based cross-sectional study was carried out in Hanuman Nagar ,Raipura village, Rural Health Training Centre (RHTC), Department of Preventive and Social Medicine, Indira Gandhi Government Medical College, [I.G.G.M.C.], Nagpur.

As per Health survey registers (April 2004 - March 2005) of PHC, Hingna, there were total 380 families in Hanuman Nagar. These families comprised 1900 population. Study area was selected randomly by lottery method for the study purpose. On the basis of pilot study finding sample size 925 subjes were adequate for true representive of study population. By simple random technique, 194 families were studied in which 925 study subjects were enrolled in this study.

\subsection{Pilot Study:}

In pilot study, the first consecutive 100 families comprising of 480 subjects were studied, Prevalence of persons having ocular morbid conditions was found to be $30.20 \%$. Estimation of sample size was done on basis of pilot study.

$$
\begin{aligned}
& \text { 2.2FORMULA } \\
& \mathrm{n}=4 \mathrm{PQ} \\
& \text { L2 } \mathrm{L} \quad-\quad \text { Allowable error } 10 \% \text { of } \mathrm{P} \\
& \mathrm{n}=4 \times 30.20 \times 69.80=924.54 \\
& \text { (3.02)2 } \\
& \mathrm{n}=925
\end{aligned}
$$

No modification in method and procedure were suggested and the study continued to cover the remaining study subjects. The pilot study was included in the full-scale study. In this way, 194 families were studied in which 925 study subjects were present.Here all houses were selected to select remaining houses. To cover all the age groups, all the members of the family were considered for the study.

\subsection{Methodology:}

Before starting the study, one month training was undertaken in Ophthalmology Department, IGGMC, Nagpur, regarding ocular examination and diagnosis of ocular morbid conditions. Approval from the Institutional Ethics Committee was obtained before the start of study.

A house to house survey was done. Study subjects were explained about the purpose \& methodology of examination. A rapport was established and co-operation was obtained. The timing of the survey was adjusted to suit the convenience of the subjects and to ensure their availability in home. The survey was done daily, mostly in the morning hours. Each individual of the family was interviewed by using pre-tested questionnaire . In case of children, parents were informant.

In each study subject, eye examination was carried out in the daylight with the help of torch.

The subjects were examined for visual acuity (V/A) (distant and near), ocular movements, cover test for strabismus, Ishihara's pseudochromatic plates for colour vision test. Visual acuity and colour vision testing was not done in children $<5$ years of age. In addition, all study subjects of 40 years and above were examined by digital tonometry; near vision was tested for presbyopia .Both eyes were examined and all the relevant clinical findings were recorded in predesigned proforma.

The standard definitions used to detect ocular morbid conditions [5,6,7]. The standard procedures and methods for ophthalmic examinations were used to detect ocular morbid conditions.

\section{Statistical Analysis}

For continuous variable mean, SD was used. Categorical data was analysed by use of percentage and significance derived by use of Chi Square test. $\mathrm{p}$ value $<0.05$ was considered statistically significant [8].

TABLE NO. 1

Prevalence of ocular morbid conditions in the study subjects

\begin{tabular}{|c|l|c|c|}
\hline \multirow{2}{*}{$*$} & \multicolumn{2}{|c|}{ Ocular morbid conditions } & \multicolumn{2}{|c|}{ Study subjects } \\
\cline { 3 - 4 } & & \multicolumn{2}{|c|}{$(\mathrm{n}=925)$} \\
\cline { 3 - 4 } & & 126 & 13.62 \\
\hline H52.1 & Myopia & 112 & 12.11 \\
\hline H11.1 & Conjunctival xerosis & 108 & 11.68 \\
\hline H52.0 & Hypermetropia & 32 & 3.46 \\
\hline H19.8 & Xerophthalmia & 27 & 2.92 \\
\hline H11.0 & Pterygium & \multicolumn{2}{c}{} \\
\hline
\end{tabular}


Study Of Some Epidemiological Determinants Of Ocular Morbid Conditions In The Rural Area Of

\begin{tabular}{|l|l|c|c|}
\hline H25.0 & Immature senile cataract & 25 & 2.70 \\
\hline H53.1 & Eye strain & 23 & 2.49 \\
\hline H25.1 & Mature senile cataract & 17 & 1.84 \\
\hline H52.4 & Presbyopia & 8 & 0.86 \\
\hline H27.0 & Aphakia & 7 & 0.76 \\
\hline S 05.0 & Ocular injury & 7 & 0.76 \\
\hline H50 & Strabismus & 5 & 0.54 \\
\hline H10.0 & Conjunctivitis & 3 & 0.32 \\
\hline H04.0 & Dacryocystitis & 2 & 0.22 \\
\hline H26 & Congenital (cataract) & 1 & 0.22 \\
\hline C69 & Melanoma & 1 & 0.11 \\
\hline H00.1 & Chalazion & 1 & 0.11 \\
\hline H01.0 & Blepharitis & 1 & 0.11 \\
\hline H02.4 & Ptosis & 1 & 0.11 \\
\hline H25.2 & Hypermature (cataract) & 2 & 0.11 \\
\hline
\end{tabular}

* From International Statistical Classification of Diseases and Related Health Problems. $10^{\text {th }}$ Revision, (WHO, Geneva 1992) [24]

TABLE NO. 2

Distribution of ocular morbid conditions and socioeconomic status (SES)

\begin{tabular}{|c|c|c|c|}
\hline \multirow[b]{2}{*}{ SES } & \multicolumn{2}{|c|}{ Study subjects } & \multirow[b]{2}{*}{ Prevalence percent } \\
\hline & No. & $\begin{array}{c}\text { With ocular morbid } \\
\text { conditions }\end{array}$ & \\
\hline Upper middle & 48 & 18 & 37.5 \\
\hline Lower middle & 40 & 22 & 55.0 \\
\hline Upper lower & 132 & 45 & 34.09 \\
\hline Lower & 705 & 212 & 30.07 \\
\hline Total & 925 & 297 & 32.11 \\
\hline
\end{tabular}

$\chi^{2}=30.81$, d.f. $=3, \mathrm{p}<0.001$.

Table no. 3

Distribution of ocular morbid conditions and personal habits

\begin{tabular}{|c|c|c|c|}
\hline \multirow[b]{2}{*}{ Personal habits } & \multicolumn{2}{|c|}{ Study subjects } & \multirow{2}{*}{$\begin{array}{c}\text { Prevalence } \\
\text { percent }\end{array}$} \\
\hline & No. & $\begin{array}{l}\text { With ocular morbid } \\
\text { conditions }\end{array}$ & \\
\hline Tobacco consumption & 106 & 79 & 74.53 \\
\hline Alcohol consumption & 13 & 7 & 53.85 \\
\hline Smoking & 7 & 7 & 100.00 \\
\hline Tobacco and alcohol consumption & 22 & 12 & 54.55 \\
\hline Tobacco consumption and smoking & 3 & 1 & 33.33 \\
\hline Alcohol consumption and smoking & 4 & 4 & 100.00 \\
\hline $\begin{array}{l}\text { Tobacco and alcohol consumption and } \\
\text { smoking }\end{array}$ & 5 & 5 & 100.00 \\
\hline No habit & 765 & 182 & 23.79 \\
\hline Total & 925 & 297 & 32.11 \\
\hline
\end{tabular}

When Tobacco consumption was compared with no habit with respect to ocular morbid conditions; X2 = 114.23, d.f. $=1, \mathrm{p}<0.001$ When Alcohol consumption was compared with no habit with respect to ocular morbid conditions. X2 $=4.74$; d.f. $=1, \mathrm{p}<0.05$, (with Yates correction) When smoking was compared with no habit with respect to ocular morbid conditions; $\mathrm{X} 2=17.92$, d.f. $=1, \mathrm{p}<0.001$, (with Yates correction). 
TABLE NO. 4

Distribution of ocular morbid conditions and type of cooking fuel predominantly used

\begin{tabular}{|l|c|c|c|}
\hline \multirow{2}{*}{$\begin{array}{c}\text { Type of cooking fuel } \\
\text { Predominantly used }\end{array}$} & No. & $\begin{array}{c}\text { With ocular morbid } \\
\text { conditions }\end{array}$ & $\begin{array}{c}\text { Prevalence } \\
\text { percent }\end{array}$ \\
\cline { 2 - 3 } & 175 & 94 & 53.71 \\
\hline Biomass & 129 & 50 & 38.76 \\
\hline LPG & 10 & 4 & 40.00 \\
\hline Kerosene stove & 314 & 148 & 47.13 \\
\hline Total & & & \\
\hline
\end{tabular}

$\chi^{2}=6.109$ (with Yates correction) d.f. $=2, \mathrm{p}<0.05$

\section{RESULTS:}

Out of 925 study subjects males constituted 504 subjects (54.49\%) while females constituted 421 subjects $(45.51 \%)$ of the study population. Maximum i.e. 221 (23.89\%) were in the age group of 15-25 years. Mean age \pm Standard Deviation was $26.51 \pm 16.97$ years.

Table 1 reveals that out of 925 study subjects examined 297 (32.11\%) study subjects were having ocular morbidity. Refractive error was seen in $242(26.16 \%)$ and cataract in $45(4.87 \%)$ study subjects.

Table No 2 shows that in the present study, no study subject belonged to upper socio-economic class. It shows the statistically significant association of ocular morbid conditions and socio-economic status (SES).

The distribution of ocular morbid conditions and personal habits as in Table 3;it reveals that when Tobacco consumption was compared with no habit with respect to ocular morbid conditions; difference was found to be statistically significant $(\mathrm{p}<0.001)$. When Alcohol consumption was compared with no habit with respect to ocular morbid conditions this difference was also found to be statistically significant $(\mathrm{p}<0.05)$.

When smoking was compared with no habit with respect to ocular morbid conditions; $\chi 2=17.92$, d.f. $=1, \mathrm{p}<0.001$, the association of smoking with ocular morbid conditions was found to be statistically significant. Minimum (23.79\%) prevalence of ocular morbid conditions was found in subjects having no habit.

Table No. 4 shows the predominant use of cooking fuel by females of 15 years of age and above and the association with ocular morbid conditions. It shows that 53.71 percent of ocular morbid conditions were found in females predominantly using biomass. $40.00 \%$ of ocular morbid conditions was found in females predominantly using Kerosene stove followed by $38.76 \%$ in those predominantly using LPG.In the present study; association of ocular morbid conditions and type of cooking fuel predominantly used was found to be statistically significant $(\mathrm{p}<0.05)$.

\section{Discussion}

Ocular morbid conditions are responsible for partial or total blindness. About $30 \%$ of the blind in India are said to lose their eye sight before they reach the age of 20 years and many under the age of 5 years. Refractive error, trachoma, conjunctivitis and malnutrition (vitamin A deficiency) are the important causes of blindness among children and the younger age groups, cataract refractive error, glaucoma and diabetes are causes of blindness in middle age, accidents and injuries can occur in all age groups but more importantly in the age group 20 to 40 years. It is essential to detect these cases at the earliest to reduce the complications and disabilities, so that these patients have disability free life expectancy. Hence, our study covers all age groups and both sexes.

The association between ocular morbid conditions and occupation was also seen in various studies for example. Wong T.Y et al (2000) found that professional or office related occupations was significantly associated with higher rates of myopia after adjustment for age and sex [9].

Ajaiyoeba A.I et al (2002) found that school children, farmers, welders and panel beaters were particularly at risk of ocular problems from injuries with potential for blindness [10].

Unskilled group constituting of labourers was compared with the rest with respect to ocular morbid conditions, $\mathrm{X} 2=29.39$, d.f. $=1, \mathrm{p}<0.001$.

Prevalence rates of ocular morbid conditions in the unskilled group was (45.93\%) similar to our study has been reported by Singh M.M et al (1997) and Sahia A, et al (2005) [11,12].

The prevalence of ocular morbid conditions in the lower middle class was $55.00 \%$ similar to Desai S, et al (1989), Dandona R et al (2001), Dandona R, et al (2002) and Ughade S.N, et al (1998) [13 to 16].

The association between personal habits like tobacco smoking and alcohol consumption and ocular morbid conditions in our study was found to be statistically significant similar to that reported by Raju P et al (2006) [17],Badrinath S.S, et al (1996) [18],Solberg Y, et al (1998) [19] and Sannapeneni, K et al 2005 [20].

It is found that during cooking particularly with biomass fuels, air has to be blown into the fire from time to time especially when the fuel is moist and the fire is smouldering. This causes considerable exposure of the eyes to 
the emanating smoke. It is believed that the toxins from biomass fuel smoke are absorbed systematically and accumulate in the lens resulting in its opacity.In our study $53.71 \%$ of ocular morbid conditions were found in females predominantly using biomass as cooking fuel.Similarly Saha A; et al ,(2005) [21] found use of cheaper cooking fuel was significantly associated with age related cataract. Similarly Mohan M ;et al (1989) observed wood use as cooking fuel as an important factor in the aetiology of age dependent cataract (OR 2.12, 95\% CI 1.03-4.34) [22]. When comparing wood only and LPG only users, the odds ratio was 3.47 (95\% CI 1.05-11.50). Mishra V.K; et al (1999) found that persons living in households using biomass fuels have a considerably higher prevalence of blindness (Partial or complete) than those living in households using cleaner fuels. (OR 1.32; 95\% CI $1.16-1.50)$ [23].

\section{Conclusion}

High prevalence of ocular morbidities were found in rural areas of Central India with greater predominance among lower socioeconomic strata and study subjects with smoking and alcohol habits and in females predominantly using biomass as cooking fuel.

\section{Recommendation}

Screening and early referral of population in need of specialized ophthalmic care is emphasized.

\section{Limitations Of The Study:}

No Ophthalmoscopy, tonometry, slit lamp examination or refraction were carried out therefore diseases of vitreous, retina, optic nerve could not be detected. Mild glaucoma, mild diseases of cornea, anterior chamber, iris may also have been missed.

\section{References:}

[1] Thylefors B. Avoidable blindness. Bull World Health Organ. 1999;77:453

[2] Balasubramaninan D, Bansal A.K. Basti S, Bhatt K.S, Murthy J.S., Rao C.M (1993), The biology of cataract. The Hyderabad cataract research group, Indian J Ophthalmol, Vol.41, No .4, P.153-171.

[3] ICMR Bulletin, (2000), Indoor air pollution in India - a major environmental and public health concern, Vol .31, No.5, P.61-68

[4] Park K (2005), Park's Textbook of Preventive and Social Medicine, Eighteenth edition, Banarsidas Bhanot Publishers, Jabalpur, P.320-323.

[5] Statye M, Reeves B, Wortham Cathereen (1993), Ocular and vision defects in pre school children, Br J Ophthalmol, Vol .77, No.4, P.228-232.

[6] Miller J.H. Stephen (1990): Parson's Diseases of the eye, Publisher : Churchill Livingstone, Robert Stevenson, 18th Edition, P.75$102,127-228$.

[7] Basak S.K (1997) Essentials of ophthalmology 1 st edition, Current books International publishers, Calcutta

[8] Mahajan B.K. and Gupta M.C. (2003) Textbook of Preventive and Social Medicine, Third edition, Jaypee Brothers medical publishers, New Delhi, P.322, P.384-386.

[9] Wong T.Y, Foster P.J, Hee J, Ng T.P., Tielsch J.M, Chew S.J, et al (2000), Prevalence and risk factors for refractive errors in adult Chinese in Singapore, Investigative Ophthalmology and Visual Science, Vol .41, P . 2486-2494.

[10] Ajaiyeoba A.I and Scott S.C.O (2002), Risk factors associated with eye diseases in Ibadan, Nigeria, African Journal of Biomedical Research, Vol.5, P.1-3.

[11] Singh M.M, Murthy G.V, Venkatraman R, Rao S.P. Nayar S, (1997) A study of ocular morbidity among elderly population in a rural area of central India, Indian J Ophthalmol, Vol .45, No .1, P .61-65.

[12] Sahai A, Malik P, (2005), Dry Eye: prevalence and attributable risk factors in a hospital based population, Indian J Ophthalmol, Vol.53, No.2, P.87-91.

[13] Desai S, Desai R, Desai N.C, Lohiya S, Bharagav G, Kumar K, (1989) School eye health appraisal, Indian J Ophthalmol, Vol.37, No .4, P.173-175

[14] Dandon R, Dandona L, (2001), Review of findings of the Andhra Pradesh eye disease study: Policy implications for eye - care services, Indian J Ophthalmol, Vol .49, P.215-234.

[15] Dandona R, Dandona L, Srinivas M, Giridhar P, Prasad M.N, Vilas K, McCarty C.A, Rao G.N, (2002), Moderate visual impairment in India: the Andhra Pradesh eye disease study, Br J Ophthalmol, Vol.86, P.373-377.

[16] Ughade S.N., Zodpey S.P, Khanolkar V.A., (1998), Risk factors for cataract: A case control study, Indian J Ophthalmol, Vol. 46, No .4, P.221-227.

[17] Raju P, George R, Sathyamangalam R.V, Arvind H, Manin B and Vijaya L, (2006), Influence of tobacco use on cataract development, Br J Ophthalmol, (July).

[18] Badrinath S.S., Sharma T, Biswas J, Srinivas V, (1996), A case control study of senile cataract in a hospital based population, Indian J Ophthalmol, Vol .44, P.213-217.

[19] Solberg Y, Rosner M, Belkin M, (1998). The association between cigarette smoking and ocular diseases, Surv Ophthalmol, Vol .42 , No .6, P.535-547.

[20] Sannapaneni K, Kovai V, R, Shamanna B.R, Rao G.N, Thomas R and Balasubramanian D, (2005) Smoking and its association with cataract : Results of the Andhra Pradesh eye disease study from India, Investigative Ophthalmology and Visual Science, Vol 46, P.58-65.

[21] Saha A, Kulkarni PK, Shah A, Patel M, Saiyed HN: Ocular morbidity and fuel use: an experience from India. Occup Environ Med 2005, 62:66-69.

[22] Mohan M, Sperduto RD, Angra SK, Milton RC, Mathur RL, Underwood BA et al.: India-US case-control study of age-related cataracts. India-US Case-Control Study Group. Arch Ophthalmol 1989, 107:670-676.

[23] Mishra V.K, Retherford R.D, Smith K.R., (1999), Biomass cooking fuels and prevalence of blindness in India. : National Family Health Survey Bulletin, No .14 (April), P.1-4.

[24] International statistical classification of diseases and related heath problems (1992), Xth Revision, WHO, Geneva. 